\title{
Teste de toxicidade e criopreservação de folículos pré-antrais ovinos isolados utilizando Glicerol, Etilenoglicol, Dimetilsulfóxido e Propanodiol
}

Regiane Rodrigues dos SANTOS ${ }^{1}$

Ana Paula Ribeiro RODRIGUES'

Sônia Helena Furtado COSTA $^{1}$

Maria Helena Tavares MATOS ${ }^{1}$

José Roberto Viana SILVA ${ }^{1}$ Juliana Jales de Hollanda CELESTINO

Fabricio Sousa MARTINS'1

Marcia Viviane Alves SARAIVA ${ }^{1}$

Mônica Aline Parente MELO'

José Ricardo de FIGUEIREDO

\section{Correspondência para:} REGIANE RODRIGUES DOS SANTOS Laboratório de Manipulação de Oócitos e Folículos Pré-antrais

Universidade Estadual do Ceará Av. Paranjana, 1700 - Itaperi 60740-000-Fortaleza-CE regianers@hotmail.com

Recebido para publicação: 12/05/2004 Aprovado para publicação: 21/09/2005

1 - Laboratório de Manipulação de Oócitos e Folículos Pré-antrais da Universidade Estadual do Ceará, Fortaleza - CE

\begin{abstract}
Resumo
O objetivo deste estudo foi avaliar folículos pré-antrais (FOPA) ovinos isolados após sua exposição e criopreservação utilizando glicerol (GLI), etilenoglicol (EG), propanodiol (PROH) ou dimetilsulfóxido (DMSO) a 1,5 e 3,0 M. Cada par ovariano de 5 ovelhas sem raça definida foi coletado em abatedouro local e submetido ao isolamento folicular. Da suspensão obtida, uma alíquota foi imediatamente destinada à análise da viabilidade folicular com o auxílio do corante vital azul de trypan. O restante da suspensão foi dividida em 16 alíquotas de $0,9 \mathrm{~mL}$, suspensas (v/v) em $\mathrm{MEM}^{+}$com EG, DMSO, GLI ou PROH a 1,5 ou 3,0 M, para teste de toxicidade e criopreservação. Após o término de cada tratamento, a viabilidade folicular foi analisada e os FOPA considerados viáveis se não corados ou não viáveis, quando corados. A análise dos dados mostrou que após o teste de toxicidade e criopreservação, em todos os crioprotetores e em ambas as concentrações, a percentagem de FOPA viáveis foi significativamente reduzida quando comparada ao controle. No teste de toxicidade, quando os crioprotetores foram comparados entre si nas mesmas concentrações, foram observadas percentagens significativamente menores de FOPA viáveis no PROH 3,0 M (38,9\%), apresentandose, portanto, mais tóxico quando comparado aos demais crioprotetores. Após criopreservação, obteve-se percentagens significativamente maiores de folículos pré-antrais viáveis quando o EG e o DMSO foram utilizados. Em conclusão, FOPA ovinos isolados podem ser criopreservados com sucesso utilizando-se DMSO e EG a 1,5 e 3,0 M
\end{abstract}

\section{Introdução}

Dezenas de milhares de folículos préantrais (FOPA) podem ser recuperados de um único ovário ovino por meio de dissociação mecânica ${ }^{1}$. Esta seria uma fonte potencialmente rica de material genético para a reprodução animal se os oócitos pudessem ser preservados e crescidos in vitro. No entanto, além da escassez de técnicas eficientes de cultivo in vitro de FOPA, torna-se necessário o desenvolvimento de protocolos para a preservação desses gametas uma vez que a manipulação imediata de um grande número de FOPA torna-se inexequível. A preservação de material biológico em nitrogênio líquido $\left(-196^{\circ} \mathrm{C}\right)$ pode ser obtida por milhares de anos ${ }^{2}$, sendo esta uma alternativa para preservar o material genético de animais de alto valor zootécnico ou em via de extinção. A criopreservação de FOPA pode ser realizada in situ (murinos ${ }^{3}$, humanos $^{4}$, caprinos ${ }^{5}$; ovinos ${ }^{6,7}$ ) ou na sua forma isolada $\left(\right.$ ovinos $\left.^{8}\right)$. A criopreservação de fragmentos de tecido ovariano tem produzido resultados animadores, como por exemplo a restauração do ciclo reprodutivo após transplante ${ }^{6,9,10,11}$, bem como o nascimento de camundongos viáveis após cultivo de FOPA in vitro ${ }^{12,13,14}$. No entanto, ainda não foi relatada a criopreservação de folículos pré-antrais 
ovinos isolados utilizando simultaneamente diferentes crioprotetores (GLI, ETG, DMSO e PROH) e concentrações (1,5 e 3,0 $\mathrm{M})$. Além disso, ainda não é conhecido em que etapa do procedimento de criopreservação (período de equilíbrio e/ ou congelação/descongelação) ocorrem as perdas foliculares.

O objetivo deste estudo foi avaliar o efeito de quatro criprotetores (GLI, DMSO, PROH e ETG), em duas concentrações (1,5 e 3,0M), sobre a viabilidade de FOPA ovinos isolados após exposição e criopreservação, quantificando as perdas foliculares em ambas as etapas.

\section{Materiais e Métodos}

\section{Origem e transporte dos ovários}

Ovários $(n=10)$ de 5 ovelhas sem raça definida (SRD) foram coletados em abatedouro local. Após a retirada dos tecidos circundantes e ligamentos, os ovários foram lavados em álcool 70\% e duas vezes em solução salina $0,9 \%$. Em seguida, cada par ovariano foi transferido para tubos contendo solução salina $0,9 \%$ e transportado ao laboratório a $20{ }^{\circ} \mathrm{C}$ em 1 hora.

\section{Isolamento folicula}

No laboratório, os ovários foram submetidos ao isolamento folicular utilizando-se o procedimento mecânico descrito por Amorim et al. Este procedimento foi realizado com o auxílio de um tissue chopper (The Mickle Laboratory Engineering CO, Gomshal, Surrey, England) ajustado para a realização de cortes seriados a intervalos de $87,5 \mathrm{~mm}$. Os fragmentos foram então colocados em tubos Falcon contendo Meio Essencial Mínimo $^{+}$(MEM; Sigma M 0268) adicionado de $10 \%$ de soro fetal bovino e suspensos 50 vezes com uma pipeta Pasteur de $1600 \mathrm{~mm}$ de diâmetro e 50 vezes com uma outra pipeta de $600 \mathrm{~mm}$ de diâmetro. A suspensão foi filtrada sucessivamente em filtros de nylon de 500 e $100 \mathrm{~mm}$.
Teste de toxicidade e Criopreservação/Descongelação A suspensão obtida contendo os folículos pré-antrais isolados foi dividida em 17 alíquotas de $0,9 \mathrm{~mL}$ cada. A primeira (T1 - controle) foi destinada para a análise da viabilidade folicular logo após o isolamento. Para isto, $5 \mathrm{~mL}$ de azul de tripan $0,4 \%$ foram adicionados a cada $100 \mathrm{~mL}$ da suspensão folicular. Após um minuto, a suspensão foi analisada e os folículos que apresentavam-se corados foram considerados mortos e, os não corados, vivos. As 16 alíquotas remanescentes foram suspensas $(\mathrm{V} / \mathrm{V}) \mathrm{em}$ $\mathrm{MEM}^{+}$com EG, DMSO, GLI ou PROH a 1,5 ou 3,0 M para teste de toxicidade (T2 T9) e criopreservação (T10 - T17). Com relação ao teste de toxicidade, este foi realizado somente expondo-se a suspensão folicular aos referidos crioprotetores a 20 ${ }^{\circ} \mathrm{C}$ por 20 minutos para posterior remoção do crioprotetor e análise. Para o procedimento de congelação, os criotubos contendo as suspensões passaram por um período de equilíbrio de 20 minutos em cada crioprotetor e concentração testados e levados para uma máquina de congelação (Freezer Control, CL 856, Cryologic Pty, Ltd., Melbourne, Austrália) a $20{ }^{\circ} \mathrm{C}$. Os criotubos foram resfriados até $-7{ }^{\circ} \mathrm{C}$ a uma velocidade de $1^{\circ} \mathrm{C} / \mathrm{min}$, sua cristalização foi induzida manualmente, e resfriados lentamente a $0,3^{\circ} \mathrm{C} / \mathrm{min}$ até $-30^{\circ} \mathrm{C}$ e em seguida a $0,15^{\circ} \mathrm{C} / \mathrm{min}$ até atingirem $-33^{\circ} \mathrm{C}$. Em seguida, os criotubos foram estocados em nitrogênio líquido por 5 dias. Após este período, a suspensão foi descongelada retirando-se os criotubos do nitrogênio líquido e expondo as amostras à temperatura ambiente por 1 minuto, e então colocados em banho-maria a $37^{\circ} \mathrm{C}$ até completa descongelação da suspensão.

Após o período de equilíbrio (teste de toxicidade) e descongelação, os crioprotetores foram removidos por meio de centrifugação das suspensões $(1000 \mathrm{rpm}$ por 2 minutos) e remoção de $0,9 \mathrm{~mL}$ da solução adicionando-se $2,7 \mathrm{~mL}$ de MEM+. Esta operação foi repetida três vezes e cada lavagem teve duração de 5 minutos. Em 
seguida, as suspensões obtidas foram avaliadas com o auxílio do azul de trypan para contar o número de folículos pré-antrais vivos e mortos. Cada tratamento foi repetido 5 vezes.

\section{Análise estatística}

Os efeitos do tipo (GLI, ETG, $\mathrm{PROH}$ e DMSO) e concentração (1,5 e 3,0 M) do crioprotetor sobre a percentagem de folículos pré-antrais viáveis em relação ao controle foram analisados utilizando o teste do Qui-quadrado. Valores foram considerados estatisticamente significativos quando $\mathrm{P}<0.05$.

\section{Resultados}

Percentagem de FOPA viáveis após teste de

\section{toxicidade e criopreservação}

Neste estudo, um mínimo de 150 FOPA por tratamento foi analisado utilizando o corante vital azul de trypan. A percentagem de FOPA viáveis no controle, após o teste de toxicidade e congelação/descongelação foi de $83,1 \%, \quad 62,3 \%$ e $65,7 \%$, respectivamente.

A figura 1 mostra a percentagem de FOPA viáveis analisados no controle, após teste de toxicidade e criopreservação. A análise estatística dos dados mostrou que houve uma redução significativa na percentagem de FOPA viáveis após exposição e criopreservação utilizando todos os crioprotetores em ambas as concentrações quando comparados ao controle.

Após o teste de toxicidade na concentração de $1,5 \mathrm{M}$, as percentagens de FOPA viáveis após a utilização de DMSO, ETG e GLI M foram similares entre si e significativamente superiores ao $\mathrm{PROH}$. Em relação à concentração de 3,0 M, o DMSO e ETG apresentaram-se similares entre si e superiores ao GLI e PROH. Quando comparou-se as concentrações utilizadas dentro de cada crioprotetor, somente para o ETG não foi observada redução significativa na percentagem de FOPA normais com o aumento da concentração de 1,5 para 3,0 M.

Após criopreservação, os FOPA criopreservados em ETG e DMSO em ambas as concentrações apresentaram percentagens significativamente maiores de FOPA viáveis. Quando comparou-se as concentrações de 1,5 e 3,0 M dentro de cada crioprotetor, somente para o ETG e DMSO não foi observada redução significativa da percentagem de FOPA viáveis com o aumento da concentração. Vale ressaltar que as percentagens significativamente menores de FOPA viáveis pós congelação/ descongelação foram obtidas quando utilizou-se o GLI 1,5 M.

Quando as comparações foram realizadas entre o teste de toxicidade e criopreservação no mesmo crioprotetor e concentração, apenas foi observada redução significativa da percentagem de FOPA viáveis na criopreservação em relação ao teste de toxicidade no GLI em ambas as concentrações.

\section{Discussão}

Realizou-se neste trabalho, o teste de toxicidade e criopreservação de FOPA ovinos isolados comparando simultaneamente o GLI, DMSO, PROH e ETG nas concentrações de 1,5 e 3,0 M. Além disso, foi possível quantificar e comparar as perdas de FOPA nas etapas de equilíbrio (teste de toxicidade) e criopreservação propriamente dita.

O presente estudo demonstrou que independente do crioprotetor (GLI, DMSO, PROH ou ETG) e concentração (1,5 ou 3,0 M) utilizados, todos têm um efeito tóxico sobre FOPA ovinos isolados. Os eventos iniciais (período de equilíbrio) durante a congelação/descongelação podem levar a severos danos ou morte celular, uma vez que a maioria dos crioprotetores que mantêm a viabilidade celular a baixas temperaturas, também possuem características tóxicas. Em geral, as células são sensíveis à criopreservação ${ }^{16}$ durante a exposição aos crioprotetores e após congelação/ 
descongelação. Este procedi-mento pode resultar em extremas flutuações no volume celular causando efeitos dele-térios durante o subsequente resfriamento ${ }^{17}$. O efeito tóxico foi acentuado quando utilizou-se o PROH a 3,0 M. De acordo com Lim et al ${ }^{18}$, o PROH possui elevada ação citotóxica observada quando utilizado em concentrações acima de 1,5 M. Com relação aos demais tratamentos, ou seja, ETG e DMSO (1,5 e 3,0 M) e GLI 1,5 M, os resultados foram similares entre si. No entanto, apesar da similaridade entre os tratamentos dentro do teste de toxicidade, o real efeito dos crioprotetores deve ser avaliado após os procedimentos de congelação/descongelação.

Analisando os FOPA após procedimentos de congelação/descongelação, observou-se uma redução significativa de folículos viáveis em relação ao controle. Quando comparou-se o teste de toxicidade com o procedimento de congelação/ descongelação, observou-se uma redução significativa da percentagem de FOPA viáveis após criopreservação em relação ao teste de toxicidade ao utilizar-se o GLI em ambas as concentrações. Portanto, excetuando-se o GLI (único crioprotetor no qual foi observado efeito significativo da criopreservação em relação ao teste de toxicidade) as perdas foliculares observadas após criopreservação já haviam ocorrido durante o período de equilíbrio. O GLI tem sido utilizado freqüentemente para a criopreservação de embriões bovinos por causa de sua baixa citotoxicidade. No entanto, pode induzir diversos danos osmóticos no citoplasma devido à sua baixa permeabilidade. De acordo com Fuku et al. ${ }^{19}$ e Mazur ${ }^{2}$, o DMSO, PROH e ETG posuem maior permeabilidade à membrana celular que o GLI, o que pode ter levado às menores taxas de FOPA viáveis quando o GLI foi utilizado. Estudando a criopreservação em tecido ovariano humano, Hovatta ${ }^{20}$ observou que o ETG penetra no tecido mais rapidamente que o PROH e DMSO e que, o GLI constitui o crioprotetor de ação mais lenta e, conseqüentemente, menos eficiente. A baixa eficiência na criopreservação observada com o GLI nas concentrações testadas aponta para a necessidade de se aumentar o período de equilíbrio para sua melhor penetração no tecido ovariano. Existem duas etapas básicas durante a criopreservação: o período de equilíbrio e a congelação/descongelação. Neste estudo, foi possível quantificar as perdas foliculares em ambas as fases. Observou-se, desta forma, que para o ETG, DMSO e PROH o período de equilíbrio utilizado não foi eficiente, pois já havia reduzido significativamente a taxa de viabilidade folicular comparada ao controle, sendo necessária a utilização de períodos ou temperaturas menores afim de diminuir os danos celulares. Quando os crioprotetores foram comparados entre si, os melhores resultados foram obtidos quando utilizouse ETG e DMSO (1,5 e 3,0 M), sugerindo que estas substâncias mantêm com maior eficiência a integridade dos FOPA após congelação/descongelação. Muitas células, especialmente as eucarióticas, são sensíveis ao choque osmótico ${ }^{21}$. Assim, crioprotetores como o DMSO e ETG quando adicionados ao meio de crio-preservação, minimizam o estresse osmótico. Os crioprotetores mais eficientes são altamente hidrofilicos ${ }^{22}$ devido à presença de grupos químicos que formam fortes pontes de hidrogênio com a água, por exemplo os sulfóxidos (DMSO). Por este motivo, muitos crioprotetors também protegem as células e suas proteínas contra a desidratação e destruição térmica. Tais crioprotetores permeáveis tornam a membrana celular mais plástica e ligam-se à água intracelular covalentemente prevenindo a desidratação excessiva e formação de grandes cristais de gelo, reduzindo a toxicidade do sal dentro da célula ${ }^{21}$.

\section{Conclusão}

Em conclusão, a análise da viabilidade folicular realizada neste trabalho demonstrou que FOPA ovinos isolados podem ser 


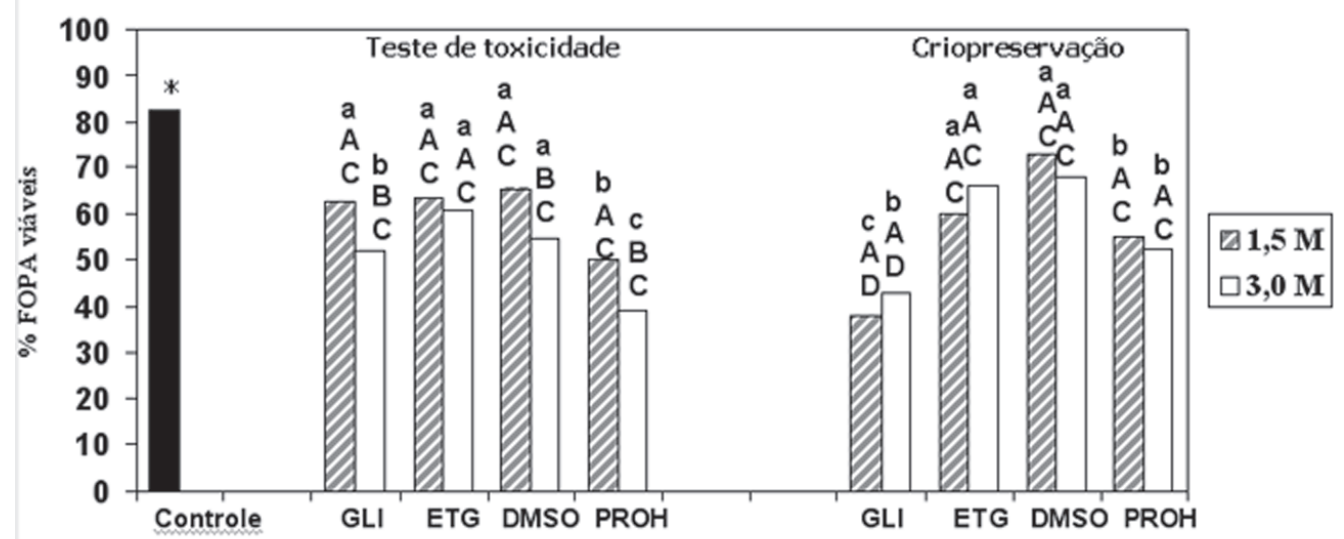

Figura 1 - Percentagem de FOPA viáveis no controle, após teste de toxicidade e criopreservação "Difere significativamente do controle;

a,b,c Diferentes letras diferem significativamente dentro do mesmo teste (teste de toxicidade ou criopreservação) e concentração; A,B Diferentes letras diferem significativamente entre as concentrações dentro de cada crioprotetor no teste de toxicidade e criopreservação;

C,D Diferentes letras diferem significativamente entre o teste de toxicidade e criopreservação dentro de cada crioprotetor e concentraçãa.

criopreservados com sucesso utilizando-se o DMSO e ETG nas concentração de $1,5 \mathrm{M}$ e 3,0 M. Com o aperfeiçoamento dos protocolos de criopreservação, será possível formar bancos de germoplasma animal para a preservação de folículos pré-antrais por período indefinido. Esse material poderá ser crioestocado e destinado, de maneira fracionada ou não, para programas de crescimento, maturação e fecundação in vitro de oócitos para posterior transferência embrionária.

\section{Agradecimentos}

Este trabalho foi financiado pelo CNPq. Regiane Rodrigues dos Santos é bolsista FUNCAP. Os autores agradecem o Dr. Edilberto Silveira - CENAUREMN e AKZONOBEL pelo suporte técnico.

\section{Toxicity test and cryopreservation of sheep isolated preantral follicles using glycerol, ethylen glycol, dimethil sulfoxyde and propanediol}

\section{Abstract}

The aim of this study was to evaluate isolated sheep preantral follicles (PF) after exposure and cryopreservation using glycerol (GLI), ethylene glycol (EG), propanediol (PROH) or dimethyl sulfoxide (DMSO) at 1.5 and 3.0 M. Each ovarian pair from 5 mixed breed adult sheeps was obtained at a local slaughterhouse and submited to follicular isolation. From the obtained suspension, one aliquot was immediately analysed with trypan blue. The remaining suspension was divided in 16 aliquots of $0.9 \mathrm{~mL}$, suspended in $(\mathrm{v} / \mathrm{v})$ in $\mathrm{MEM}^{+}$with EG, DMSO, GLI or PROH at 1.5 or $3.0 \mathrm{M}$ to the toxicity test and cryopreservation. After the end of each treatment, the follicular viability was analysed and the PF were classified as viable if not dyed or not viable if dyed with trypan blue. The analysis of the results showed that after the toxicity test and cryopreservation, using all cryoprotectants and at both concentrations, the percentage of viable PF was significantly reduced when compared to the control. At the toxicity test, when the cryoprotectants were compared at the same concentrations, the lowest percentage of viable preantral follicles was obtained when $3.0 \mathrm{M} \mathrm{PROH}$
Key-words:

Preantral follicles. Sheep.

Toxicity test.

Cryopreservation. 
$(38,9 \%)$ was used, being, more toxic when compared to the others cryoprotectants. After cryopreservation, significantly higher percentual of viable PF was observed when the EG and DMSO were used. In conclusion, sheep PF can be cryopreserved successfully using DMSO and EG at 1.5 and $3.0 \mathrm{M}$.

\section{Referências}

1 AMORIM, C. A. Estudo da população de folículos ovarianos pré-antrais ovinos: desenvolvimento de uma nova biotécnica para o isolamento e caracterização folicular. 1998. 74p. Dissertação (Mestrado) Universidade Estadual do Ceará, Fortaleza, 1998.

2 MAZUR, P. Freezing of living cells: mechanisms and implications. American Physiological Society, 1984, Bethesda: p. 125-142,

3 COX, S. L.; SHAW, J.; JENKIN, G. Transplantation of cryiopreserved fetal ovarian tissue to adult recipient in mice. Journal of Reproduction and Fertility, v. 107, p. 315-322, 1996.

4 OKTAY, K. et al. Cryopreservation of immature human oocytes and ovarian tissue: an emerging thecnology? Fertility and Sterility, v. 353, p. 1-7, 1998.

5 RODRIGUES, A. P. R. et al. Cryopreservation of caprine ovarian tissue using glycerol and ethylene glycol. Theriogenology, v.61, n.6, p.1009-1024, 2004.

6 SALLE, B. et al. Restoration of ovarian steroid secretion and histologic assessment after freezing, thawing, and autograft of a hemi-ovary in sheep. Fertility and Sterility, v. 72 , p. $366-370,1999$

7 SALLE, B. et al. Freezing, thawing, and autograft of ovarian fragments in sheep: preliminary experiments and histologic assesment, Fertility and Sterility, v. 70, p. 124-128, 1998

8 AMORIM, C. A. Criopreservação de oócitos inclusos em folículos primordiais isolados a partir de ovários ovinos. 2003. 182p. Tese (Doutorado) - Universidade de Santa Maria, Santa Maria, 2003.

9 HARP, R. et al. Cryopreservation of murine ovarian tissue. Cryobiology, v. 31, p. 336-343, 1994.

10 CANDY, C. J.: WOOD, M. J.; WHITTINGHAN D. G. Follicular development in cryopreserved marmoset ovarian tissue after transplantation. Human Reproduction, v. 9, p. 2334-2338, 1995

11 BAIRD, D. T. et al. Long-term ovarian function in sheep after ovariectomy and transplantation of autografts stored at $-196{ }^{\circ} \mathrm{C}$. Endocrinology, v. 140, p. 462-471, 1999.

12 CARROLL, J. GOSDEN, R. G. Transplantation of frozen-thawed mouse primordial follicles. Human Reproduction, v. 8, p. 1163-1167, 1993

13 GUNASENA, K. T.; VILLINES, P. M.; CRITSER, E. S.; CRITSE, J. K. Live births after autologous transplant of cryopreserved mouse ovaries. Human Reproduction, v. 12, p. $101-106,1997$ a

14 GUNASENA, K.T. et al. Allogeneic and Xenogeneic transplantation of cryopreserved ovarian tissue to athymic mice. Biology Reproduction, v. 57, p. 226231, $1997 \mathrm{~b}$.

15 AMORIM, C. A. et al. Quantitative and qualitative analysis of the effectiveness of a mechanical method for the isolation of preantral follicles from ovine ovaries, Theriogenology, v. 53,p. 1251-1262, 2000.

16 ASADA, M. et al. In vitro maturation and ultrastructural observation of cryopreserved minke whale (Balaenoptera acutorostrata). Biology of Reproduction, v. 62 , p. $253-259,2000$

17 PAYNTER, S. J. et al. Cryopreservation of bovine ovarian tissue: structural normality of follicles after thawing an culture in vitro. Cryobiology. v. 38, p. 301309. 1999.

18 LIM, J. M.; et al. Development of in vitro matured bovine oocytes after cryopreservation wth different cryoprotectants. Theriogenology, v. 51, p. 1303-1310, 1999.

19 FUKU, E.; et al. In vitro fertilization and development of frozen-thawed bovine oocytes. Cryobiology, v. 29 p.485-492, 1992

20 HOVATTA, O. Cryopreservation and culture of human primordial ovarian follicles. Mollecular and Cellular Endocrinology, v. 169, p. 95-97, 2000

21 HUBÁLEK, Z. Protectants used in the cryopreservation of microorganisms. Cryobiology. V. 46, p. 205-229, 2003

22 DOEBLER, G. F. Cryoprotective compounds: review and discussion of structure and function. Cryobiology, v. 3, p. $2-11,1966$ 